\title{
Fate of Diuron and Terbuthylazine in Soils Amended with Two-Phase Olive Oil Mill Waste
}

\author{
A. Cabrera,${ }^{\dagger}$ Lucia Cox,$*{ }^{*}{ }^{\dagger}$ P. Velarde, ${ }^{\dagger}$ William C. Koskinen,${ }^{\S}$ and \\ JUAN CORNEJO ${ }^{\dagger}$
}

Instituto de Recursos Naturales y Agrobiología de Sevilla IRNAS CSIC, P.O. Box 1052, 41080

Sevilla, Spain, and Department of Soil, Water, and Climate, University of Minnesota,

1991 Upper Buford Circle, St. Paul, Minnesota 55108

\begin{abstract}
The addition of organic amendments to soil increases soil organic matter content and stimulates soil microbial activity. Thus, processes affecting herbicide fate in the soil should be affected. The objective of this work was to investigate the effect of olive oil production industry organic waste (alperujo) on soil sorption-desorption, degradation, and leaching of diuron [3-(3,4-dichlorophenyl)-1,1-dimethylurea] and terbuthylazine [ $N^{2}$-tert-butyl-6-chloro- $N^{4}$-ethyl-1,3,5-triazine-2,4-diamine], two herbicides widely used in olive crops. The soils used in this study were a sandy soil and a silty clay soil from two different olive groves. The sandy soil was amended in the laboratory with fresh (uncomposted) alperujo at the rate of $10 \% \mathrm{w} / \mathrm{w}$, and the silty clay soil was amended in the field with fresh alperujo at the rate of $256 \mathrm{~kg}$ per tree during 4 years and in the laboratory with fresh or composted alperujo. Sorption of both herbicides increased in laboratory-amended soils as compared to unamended or field-amended soils, and this process was less reversible in laboratory-amended soils, except for diuron in amended sandy soil. Addition of alperujo to soils increased half-lives of the herbicides in most of the soils. Diuron and terbuthylazine leached through unamended sandy soil, but no herbicide was detected in laboratory-amended soil. Diuron did not leach through amended or unamended silty clay soil, whereas small amounts of terbuthylazine were detected in leachates from unamended soil. Despite their higher sorption capacity, greater amounts of terbuthylazine were found in the leachates from amended silty clay soils. The amounts of dissolved organic matter from alperujo and the degree of humification can affect sorption, degradation, and leaching of these two classes of herbicides in soils. It appears that adding alperujo to soil would not have adverse impacts on the behavior of herbicides in olive production.
\end{abstract}

KEYWORDS: Diuron; terbuthylazine; soil; organic amendment; alperujo

\section{INTRODUCTION}

Olive is one of the most important crops in the Mediterranean region, where $97 \%$ of the world's olive oil is produced (1). Spain is the main olive oil producing country in the world, followed by Italy. In the early 1990s, a two-phase centrifugation process was introduced for olive oil extraction. This process extracts more oil from the olives and consumes less water and energy as compared to other processes and does not produce olive mill wastewater (2). The two-phase process for olive oil extraction produces a solid waste (alperujo), which is rich in organic matter, including lignin $(3,4)$. Large amounts of this residue are generated in short periods of time: in Spain alone, this new system generates approximately $4000000 \mathrm{Mg}$ per year of alperujo, usually from November to January, and represents a major potential environmental problem.

* Corresponding author: e-mail, lcox@irnase.csic.es.

†nstituto de Recursos Naturales y Agrobiología de Sevilla IRNAS CSIC.

$\S$ University of Minnesota.
The soils of the countries of the Mediterranean region are characterized by a low organic matter (OM) content (5). To improve the amount of organic matter in these soils, the use of organic amendments, such as sewage sludge, manure, and urban waste, has been suggested. Alperujo has a very high organic matter content (90\%); therefore, its use as soil amendment has been proposed to enrich soils poor in organic matter and as a solution for its disposal without any expensive chemical or thermal treatment $(6,7)$. Also, this residue has the advantage of being free of pathogens and heavy metals. The application of olive mill wastes to the land, either raw or after composting, properly mixed, and incorporated at acceptable loading rates, might constitute an extremely effective contribution to increasing crop yields and to maintaining or improving soil fertility $(8,9)$.

Diuron and terbuthylazine are commonly used herbicides in olive tree cultures in Spain. Diuron is a substituted-urea herbicide used to control a wide variety of annual and perennial weeds. It is absorbed by plant roots and interferes in the 
photosynthetic process in the Hill reaction. It is used on many agricultural crops and also for long-term pre-emergence weed control in noncrop areas (10). It is relatively persistent in soil with half-lives from 1 month to 1 year (11). Microbial degradation is considered to be the primary mechanism for its dissipation from soil $(12,13)$. Diuron has been detected in surface waters at concentrations of $>5 \mu \mathrm{g} / \mathrm{L}$ (14).

Terbuthylazine is a chloro- $S$-triazine herbicide used for preemergence and postemergence weed control (15). It is absorbed by roots and inhibits the Hill reaction and $\mathrm{CO}_{2}$ sorption in the chlorophyllic function. Triazines are weak bases with low water solubility. The main degradation process is microbial (16-18). The main terbuthylazine metabolites, formed by dealkylation (desethylterbuthylazine) and hydroxylation (2-hydroxydesethylterbuthylazine), and the parent compound have been detected in groundwater and are considered to be potential pollutants for aquifer contamination (19).

It is known that sorption-desorption, leaching, and dissipation of chemicals in soils are influenced by the soil OM content. Increased $\mathrm{OM}$ in soil generally results in greater pesticide sorption, decreased leaching, and greater persistence in soil. Increased sorption may decrease the bioavailability of the pesticides, resulting in inadequate pest control. These effects have been observed in soils amended with sewage sludge and carbon-rich waste materials $(20,21)$. The aim of this work was to determine the influence of the two-phase olive oil mill waste (alperujo), when added to soils as amendment, on the soil processes affecting the bioavailability, that is, sorptiondesorption, degradation, and leaching, of the herbicides diuron and terbuthylazine.

\section{MATERIALS AND METHODS}

Herbicides. Diuron [3-(3,4-dichlorophenyl)-1,1-dimethylurea) (purity $=99 \%$ ), purchased from Dr. Ehrenstorfer GmbH (Augsburg, Germany) is a crystalline colorless solid, which has solubility in water of 36.4 $\mathrm{mg} \mathrm{L}{ }^{-1}$ at $25^{\circ} \mathrm{C}$ and $\log K_{\mathrm{ow}}\left(25^{\circ} \mathrm{C}\right)$ of $2.85 \pm 0.03(22)$. $\left[{ }^{14} \mathrm{C}\right]$ Diuron (5.43 $\mathrm{MBq} / \mathrm{mg},>95 \%$ radiochemical purity) was purchased from IZOTOP Institute of Isotopes Co. (Budapest, Hungary). Terbuthylazine ( $N^{2}$-tert-butyl-6-chloro- $N^{4}$-ethyl-1,3,5-triazine-2,4-diamine) (99\% purity) was also purchased from Dr. Ehrenstorfer GmbH. It is a colorless powder with a water solubility of $8.5 \mathrm{mg} \mathrm{L}^{-1}$ at $20{ }^{\circ} \mathrm{C}$ and $\log K_{\text {ow }}$ of $3.21(22)$. $\left[{ }^{14} \mathrm{C}\right]$ Terbuthylazine $(1.99 \mathrm{MBq} / \mathrm{mg}$ and $94.3 \%$ radiochemical activity) was kindly supplied by Syngenta (Basel, Switzerland).

Soils and Organic Amendments. Two soils were used in this study: a sandy soil (SS) (pH 8.4, 0.63\% OM, 20\% clay, $71 \%$ sand) from an olive grove located in Coria del Rio (Sevilla, Spain) and a silty clay soil (SC) ( $\mathrm{pH} 8.3,1.84 \% \mathrm{OM}, 52 \%$ clay, $6 \%$ sand) from an olive grove located in Mengíbar (Jaen, Spain). Soil SC was amended with alperujo from Mengíbar in the field (FA) from 2002 to 2005 at a rate of $18000 \mathrm{~kg} \mathrm{ha}^{-1}$ (SC+FA). Soil SC amended in the field (SC+FA) and unamended soils SC and SS were sampled with a spade, air-dried, and sieved to pass a $2 \mathrm{~mm}$ mesh. Unamended SS and SC soils were amended in the laboratory $(10 \% \mathrm{w} / \mathrm{w})$ with the same alperujo added in the field ( $\mathrm{SS}+\mathrm{A}$ and $\mathrm{SC}+\mathrm{A}$, respectively). Alperujo had the following properties: $\mathrm{pH} 5.8,93.2 \% \mathrm{OM}, 25 \mathrm{~g} \mathrm{~kg}^{-1}$ dissolved organic carbon (DOC), and $\mathrm{C} / \mathrm{N}=18.3$. Unamended SC soil was also amended in the laboratory with a $10 \% \mathrm{w} / \mathrm{w}$ composted alperujo (SS+CA) from the same source. This alperujo was composted by air-drying fresh alperujo in a tank to favor the fermentation process and to reduce polyphenols. Composted alperujo had the following properties: $\mathrm{pH} 7.9,49.2 \% \mathrm{OM}$, $3000 \mu \mathrm{g} \mathrm{g}^{-1}$ DOC, and $\mathrm{C} / \mathrm{N}=16.5$. After composting, olive tree prunings and leaves were added to facilitate aeration. The amendment was weighed and added to the soil, and the mixture was sieved twice with a $2 \mathrm{~mm}$ sieve to homogenize the amendment and soil. OM of the soil samples (unamended and amended) and amendments (uncomposted alperujo and composted alperujo) was determined by dichromate oxidation (23), soil $\mathrm{pH}$ was determined in a 1:2 (w/w) soil/deionized water mixture, and texture was determined by sedimentation.
The organic amendments were further characterized by fluorescence spectroscopy. The DOC from alperujo and composted alperujo was obtained by shaking with a $0.1 \mathrm{M} \mathrm{CaCl}_{2}$ solution, which minimized the extraction of clay and mimicked the ionic strength of the pore water (24). Suspensions were shaken for $15 \mathrm{~min}$ at room temperature, centrifuged at $1000 \mathrm{~g}$ for $15 \mathrm{~min}$, and then filtered through a $0.4 \mu \mathrm{m}$ pore polycarbonate filter. DOC was measured with a Shimadzu TOC5050A Total Carbon Analyser (Duisburg, Germany). The fluorescence spectra, from 300 to $480 \mathrm{~nm}$, were obtained in a Varian Cary Eclipse fluorescence spectrophotometer (Palo Alto, CA) using $1 \mathrm{~cm}$ cuvettes excited at $254 \mathrm{~nm}$. A humification index (HIX) was calculated from the fluorescence data as (25):

$$
\mathrm{HIX}=\sum_{\mathrm{Wl}=435}^{480} I_{\mathrm{Wl}} / \sum_{\mathrm{Wl}=300}^{345} I_{\mathrm{Wl}}
$$

where $\mathrm{Wl}$ is the wavelength in nanometers and $I_{\mathrm{Wl}}$ is the fluorescence intensity at this wavelength.

Sorption-Desorption Studies. Duplicate samples (5 g) of unamended and amended soils were treated with $10 \mathrm{~mL}$ of diuron and terbuthylazine solutions (initial concentrations, $C_{\mathrm{i}}$, ranged from 5 to $50 \mu \mathrm{M}$ in $0.01 \mathrm{M} \mathrm{CaCl}_{2}$ ). Previously, it was determined that equilibrium was reached in $<24 \mathrm{~h}$ and that no measurable degradation occurred during this period. Equilibrium concentrations $\left(C_{\mathrm{e}}\right)$ in the supernatants after $24 \mathrm{~h}$ of equilibration time were determined by HPLC under the following conditions: Nova-Pack column, $150 \mathrm{~mm}$ length $\times 3.9 \mathrm{~mm}$

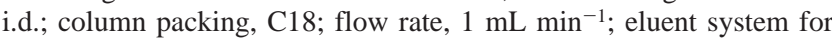
diuron 60:40 water/acetonitrile mixture and UV detection at $250 \mathrm{~nm}$ and for terbuthylazine 50:50 water/acetonitrile mixture and detection at $222 \mathrm{~nm}$. Differences between $C_{\mathrm{i}}$ and $C_{\mathrm{e}}$ were assumed to be the amounts sorbed (Cs). Sorption isotherms were fitted to the Freundlich equation, $C_{\mathrm{s}}=K_{\mathrm{f}} C_{\mathrm{e}}{ }^{1 / n_{\mathrm{f}}}$, and sorption coefficients $K_{\mathrm{f}}$ and $1 / n_{\mathrm{f}}$ calculated. Sorption coefficients $K_{\mathrm{f}}$ normalized to organic carbon (OC) content of the soils $\left(K_{\mathrm{oc}}\right)$ were also calculated, $K_{\mathrm{oc}}=K_{\mathrm{f}} / \% \mathrm{OC} \times 100$.

Herbicide desorption was made with successive washings (three times) with $0.01 \mathrm{M} \mathrm{CaCl}_{2}$ of the soil that was initially equilibrated with $50 \mu \mathrm{M}$ herbicide concentration for $24 \mathrm{~h}$. Desorption isotherms were fitted to the Freundlich equation, and the hysteresis coefficient was calculated, $H=\left[\left(1 / n_{\mathrm{f}, \mathrm{des}}\right) /\left(1 / n_{\mathrm{f}, \mathrm{sor}}\right)\right] \times 100$.

Degradation Studies. Duplicate samples (500 g) of each soil were treated with an ethanol solution of diuron or terbuthylazine to give a final concentration of $3 \mathrm{mg} \mathrm{kg}^{-1}$ of dry soil. After moisture contents had been adjusted to $40 \%$ of soil water-holding capacity, soil samples were thoroughly mixed, transferred to glass jars, capped, and incubated in the dark at $20 \pm 2{ }^{\circ} \mathrm{C}$ for 33 days. Moisture contents were maintained at a constant level throughout the experiment by adding distilled water as necessary. Soils were sampled periodically and diuron and terbuthylazine extracted by shaking $5 \mathrm{~g}$ of soil with $10 \mathrm{~mL}$ of methanol for 24 h. Recoveries were $>90 \%$. Methanol extracts were analyzed by HPLC as described above. Diuron and terbuthylazine dissipation curves in original and amended soils were fitted to first-order kinetics $\left(C=C_{\mathrm{i}}\right.$ $\left.\mathrm{e}^{-K t}\right)$ and half-lives $\left(t_{1 / 2}\right)$ calculated.

Portions ( $20 \mathrm{~g}$ ) of SC soil (unamended and amended in the laboratory $\mathrm{SC}+\mathrm{A}$ ) were placed in $250 \mathrm{~mL}$ biometer flasks and treated with 0.1 $\mathrm{mL}$ of an ethanol solution of $\left[\right.$ ring-UL- $\left.{ }^{14} \mathrm{C}\right]$ diuron or terbuthylazine $(1682 \mathrm{~Bq})$ and nonlabeled herbicide to give a concentration of $3 \mathrm{mg}$ $\mathrm{kg}^{-1}$ of dry soil. After evaporation of the solvent, the moisture content was adjusted to $-0.33 \mathrm{kPa}$ and maintained at constant level throughout the experiment. The flasks were closed with rubber stoppers and incubated at $20^{\circ} \mathrm{C}$ for a period of 6 weeks. The side arm of the biometer flask contained $1 \mathrm{~mL}$ of $1 \mathrm{M} \mathrm{NaOH}$ to trap the ${ }^{14} \mathrm{CO}_{2}$ released during the experiment. The $\mathrm{NaOH}$ solution was sampled periodically and replaced with fresh solution. The amount of ${ }^{14} \mathrm{CO}_{2}$ in the vials was determined by mixing $1 \mathrm{~mL}$ of $\mathrm{NaOH}$ solution with $5 \mathrm{~mL}$ of Beckman Ready Safe Scintillation cocktail and counting radioactivity using a LD 5000 TD Beckman liquid scintillation analyzer.

For photolysis studies, $100 \mathrm{~mL}$ of diuron and terbuthylazine aqueous solutions $\left(10 \mathrm{mg} \mathrm{L}^{-1}\right)$ was irradiated in $250 \mathrm{~mL}$ quartz flasks for $48 \mathrm{~h}$ in a Suntest photoreactor equipped with a xenon lamp and a permanent filter selecting wavelength $>290 \mathrm{~nm}$. This apparatus exhibits a radiation 
Table 1. Diuron and Terbuthylazine Sorption-Desorption Coefficients and Half-Lives $\left(t_{1 / 2}\right)$ in Dissipation Studies

\begin{tabular}{|c|c|c|c|c|c|c|c|c|c|}
\hline & soil pH/\%OM & 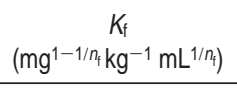 & $K_{o c}$ & $1 / n_{f}$ & $\begin{array}{c}R^{2} \\
\text { SORP }\end{array}$ & $\begin{array}{c}R^{2} \\
\text { DESORP }\end{array}$ & $H(\%)$ & $t_{1 / 2}$ (days) & $R^{2}\left(t_{1 / 2}\right)$ \\
\hline diuron & $\begin{array}{l}\text { SS 8.4/0.63 } \\
\text { SS+A 6.8/4.80 } \\
\text { SC 8.2/1.84 } \\
\text { SC+A 7.9/4.27 } \\
\text { SC+CA 7.9/4.51 } \\
\text { SC+FA 8.5/2.82 }\end{array}$ & $\begin{array}{l}2.50(2.37-2.65)^{a} \\
10.0(9.7-10.3) \\
4.31(4.01-4.62) \\
10.3(9.6-11.1) \\
7.74(7.21-8.31) \\
3.69(3.52-3.87)\end{array}$ & $\begin{array}{l}685(649-726) \\
360(348-371) \\
404(376-433) \\
415(386-447) \\
296(276-318) \\
226(215-237)\end{array}$ & $\begin{array}{l}0.79 \pm 0.02^{b} \\
0.87 \pm 0.02 \\
0.84 \pm 0.03 \\
0.96 \pm 0.05 \\
0.97 \pm 0.04 \\
0.88 \pm 0.02\end{array}$ & $\begin{array}{l}1.00 \\
1.00 \\
1.00 \\
0.99 \\
0.99 \\
0.99\end{array}$ & $\begin{array}{l}0.97 \\
1.00 \\
1.00 \\
0.98 \\
0.98 \\
1.00\end{array}$ & $\begin{array}{l}62.2 \\
68.4 \\
60.7 \\
54.4 \\
32.7 \\
67.5 \\
\end{array}$ & $\begin{array}{l}24.0(22.4-25.7)^{a} \\
342(125-463) \\
103(81.6-141) \\
150(96.4-333) \\
155(112-252) \\
61.9(56.84-67.90)\end{array}$ & $\begin{array}{l}0.98 \\
0.08 \\
0.79 \\
0.52 \\
0.63 \\
0.97\end{array}$ \\
\hline terbuthylazine & $\begin{array}{l}\text { SS 8.4/0.63 } \\
\text { SS+A 6.8/4.80 } \\
\text { SC 8.2/1.84 } \\
\text { SC+A 7.9/4.27 } \\
\text { SC+CA 7.9/4.51 } \\
\text { SC+FA 8.5/2.82 }\end{array}$ & $\begin{array}{l}1.29(1.07-1.57) \\
17.0(16.3-17.8) \\
2.60(2.29-2.89) \\
12.0(11.3-12.8) \\
8.70(7.65-9.89) \\
2.50(2.35-2.78)\end{array}$ & $\begin{array}{l}353(293-430) \\
611(585-639) \\
244(215-271) \\
485(456-518) \\
333(292-378) \\
153(144-170)\end{array}$ & $\begin{array}{l}0.95 \pm 0.07 \\
0.96 \pm 0.04 \\
0.96 \pm 0.05 \\
1.15 \pm 0.06 \\
1.05 \pm 0.09 \\
0.98 \pm 0.04\end{array}$ & $\begin{array}{l}0.98 \\
1.00 \\
0.99 \\
1.00 \\
0.98 \\
1.00\end{array}$ & $\begin{array}{l}0.96 \\
0.60 \\
1.00 \\
0.69 \\
0.96 \\
1.00\end{array}$ & $\begin{array}{l}28.1 \\
1.67 \\
60.5 \\
17.9 \\
56.9 \\
64.5\end{array}$ & $\begin{array}{c}110(103-108) \\
87.1(79.0-97.4) \\
34.3(30.7-38.8) \\
109(93.5-132) \\
88.4(76.1-108) \\
50.8(48.2-53.7)\end{array}$ & $\begin{array}{l}0.98 \\
0.96 \\
0.95 \\
0.92 \\
0.89 \\
1.00\end{array}$ \\
\hline
\end{tabular}

${ }^{a}$ Numbers in parentheses are standard errors about the mean $K_{\mathrm{f}}$ or $t_{1 / 2} .{ }^{b}$ Numbers are mean $1 / n_{\mathrm{f}} \pm$ standard deviation.

very close to that of natural sunlight (26). Flasks were sampled periodically, and herbicide concentration was determined by HPLC. Photodegradation curves of diuron and terbuthylazine as a function of irradiation time were fitted to first-order kinetics and half-lives calculated.

In the case of diuron, photolysis studies with unamended and amended SS soil were also performed. Duplicate amounts of SS and $\mathrm{SS}+\mathrm{A}$ soils $(5 \mathrm{~g})$ were treated with diuron $\left(10 \mathrm{mg} \mathrm{kg}^{-1}\right)$ and moisture content adjusted to $100 \%$ of their soil water-holding capacity in $4 \mathrm{~cm}$ diameter dishes, which were irradiated for $48 \mathrm{~h}$ in the Suntest photoreactor. Moisture content was maintained constant by the addition of water after $30 \mathrm{~min}$ of irradiation. After 2, 6, 12, 24, and $48 \mathrm{~h}$ of irradiation, soil samples were extracted with methanol $(1: 2 \mathrm{w} / \mathrm{v})$ and extracts analyzed by HPLC for their herbicide content. Photodegradation curves of diuron in SC and SC+A soils as a function of irradiation time were fitted to first-order kinetics and half-lives calculated.

Leaching Studies. Duplicate columns (3.1 cm i.d.) were hand-packed with amended and unamended soils to a height of $20 \mathrm{~cm}$ soil in each column. Glass wool was placed at the bottom of the column to avoid soil losses, and sea sand was added at the top of the soil. After saturation of the soils with $0.01 \mathrm{M} \mathrm{CaCl}_{2}$, solutions of diuron or terbuthylazine in methanol were added to the soil in the column at a rate of $3 \mathrm{~kg}$ $\mathrm{ha}^{-1}$. After $24 \mathrm{~h}$, enough time for the methanol to evaporate, $10 \mathrm{~mL}$ of $0.01 \mathrm{M} \mathrm{CaCl}_{2}$ was added daily and the leachates were collected during 30 days. The leachates were analyzed by HPLC, as previously described. At the end of the leaching study, soils were taken out of the columns with $\mathrm{N}_{2}$ and sectioned into $5 \mathrm{~cm}$ increments corresponding to different depths, and the herbicides were extracted with methanol. The extracts were analyzed by HPLC.

\section{RESULTS AND DISCUSSION}

Sorption-Desorption Studies. Diuron sorption-desorption isotherm coefficients in the original and amended SS and SC soils are given in Table 1. In laboratory-amended sandy soil (SS+A), the addition of alperujo amendment increased $\mathrm{OM}$ by a factor of 8 and diuron sorption $K_{\mathrm{f}}$ value by a factor of 4 . In laboratory-amended silty clay soil $(\mathrm{SC}+\mathrm{A})$, there was a similar increase $(2 \times)$ in both $\mathrm{OM}$ and $K_{\mathrm{f}}$. Composted alperujo has much lower organic matter and DOC contents $\left(49.2 \%, 3 \mathrm{~g} \mathrm{~kg}^{-1}\right.$, respectively) than alperujo (93.2\%, $25 \mathrm{~g} \mathrm{~kg}^{-1}$, respectively), although this OM has a higher HIX (13) than alperujo (HIX = $3)$. This results in lower sorption coefficient for $\mathrm{SC}+\mathrm{CA}$ than for $\mathrm{SC}+\mathrm{A}$. In field-amended silty clay $(\mathrm{SC}+\mathrm{FA})$, sorption of diuron was similar to that in unamended soil SC, despite a $50 \%$ increase in OM. These data show that both source and amount of OM can affect diuron sorption $(27,28)$, as also indicated by the variability in $K_{\mathrm{oc}}$ values (Table $\mathbf{1}$ ).

Alperujo amendments had a similar, but more pronounced, effect on terbuthylazine. $K_{\mathrm{f}}$ increased by a factor of 13 in laboratory-amended SS soil as compared with the 8-fold increase in OM. In laboratory-amended silty clay soil $(\mathrm{SC}+\mathrm{A})$, there was a 5 -fold increase in $K_{\mathrm{f}}$ as opposed to the $2 \times$ increase in $\mathrm{OM}$. Similarly to diuron, composted alperujo $(\mathrm{SC}+\mathrm{CA})$ rendered lower sorption coefficients, and in field-amended siltt clay (SC+FA) sorption of terbuthylazine was similar to that in unamended soil SC, despite a 50\% increase in OM. In contrast to diuron, $K_{\mathrm{oc}}$ values for terbuthylazine increased in every laboratory soil upon amendment (Table 1).

For both herbicides, higher hysteresis coefficients (higher reversibility) were observed in SC than in SS soil, which is not in accordance with SC higher sorption capacity (Table 1). For SS soil, amendment with alperujo slightly increased diuron hysteresis coefficientes, whereas these coefficients greatly decreased in the case of terbuthylazine, which indicates a very high increase in irreversibility upon amendment. This can be attributed in part to the higher affinity of terbuthylazine for organic matter in $\mathrm{SS}+\mathrm{A}$ soil than in unamended $\mathrm{SS}$ soil: $K_{\mathrm{oc}}$ for terbuthylazine increased upon amendment by a factor of 1.7 , whereas $K_{\mathrm{oc}}$ for diuron decreased upon amendment by a factor of 2 .

In the case of laboratory-amended SC soil, hysteresis coefficients decreased upon amendment for both herbicides, suggesting lower reversibility, whereas in the field-amended soil hysteresis coefficients slightly increased. One interesting difference between the sorption behavior of diuron and that of terbuthylazine in organically amended soils is the lower hysteresis coefficient for diuron in the soil amended with composted alperujo SC $+\mathrm{CA}$ of lower sorption capacity than in $\mathrm{SC}+\mathrm{A}$. In the case of terbuthylazine we find the contrary, higher irreversibility in $\mathrm{SC}+\mathrm{A}$ of higher sorption capacity (Table 1). The higher DOC content of alperujo together with the more polar character of the herbicide diuron when compared to terbuthylazine (higher water solubility and lower $K_{\mathrm{ow}}$ than terbuthylazine) could account for this. The greater affinity of diuron for the high amount of DOC present in alperujo would give rise to a higher reversibility of diuron sorption on $\mathrm{SC}+\mathrm{A}$ soil than on $\mathrm{SC}+\mathrm{CA}$ soil, in which the amount of DOC is lower and also less polar, as indicated by its higher HIX. Previous results seem to corroborate this hypothesis, because we have found that diuron is able to form stable complexes with DOC from organic amendments (28).

Degradation Studies. Incubation Studies in the Dark. The increase in organic matter content upon amendment has been shown to promote biodegradation by enhancing microbial populations and activities (29-32). However, we do not observe this effect with alperujo and the herbicides studied. In the case 

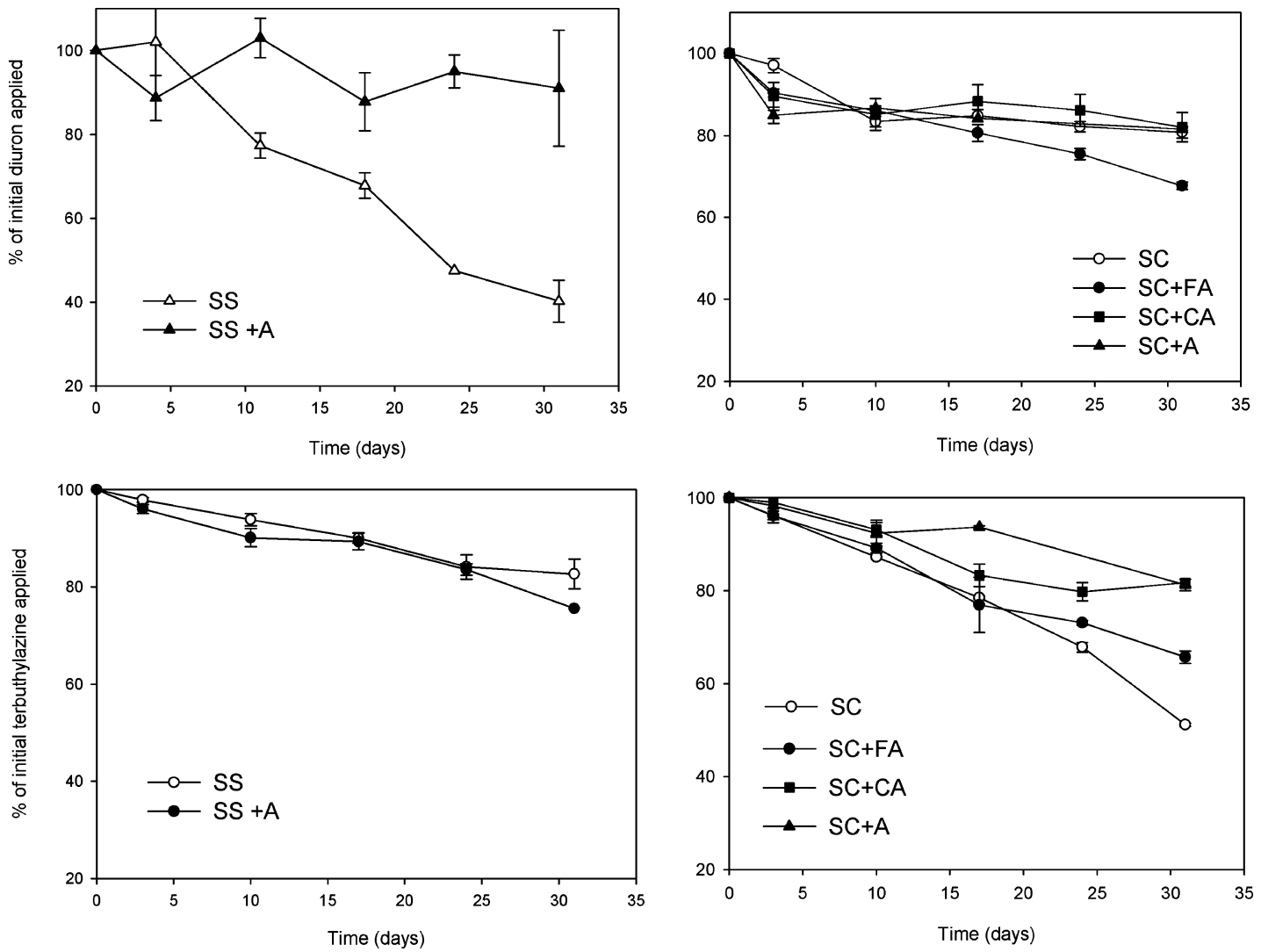

Figure 1. Dissipation of diuron and terbuthylazine in unamended and amended SS and SC soils in the dark.

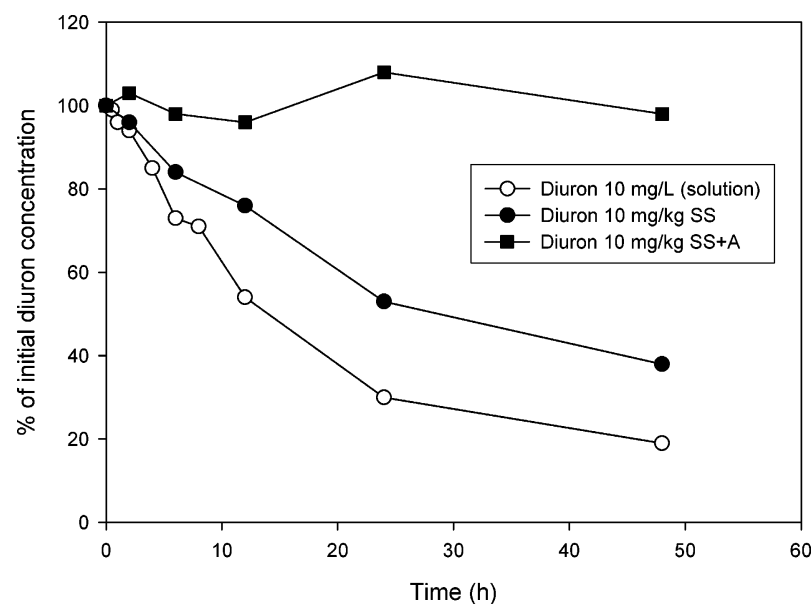

Figure 2. Diuron photodegradation in solution and in unamended and amended SS soils (error bars are smaller than symbols).

of diuron (Figure 1), the shortest half-life was observed in unamended sandy soil SS (Table 1), which had low sorption capacity. When SS was amended with alperujo, diuron concentration remained unaffected after a 30 day incubation period (Figure 1; Table 1). This can be attributed to the very high increase in diuron sorption upon amendment in this soil (Table 1), because sorption protects herbicides from biodegradation (33-35). Little difference was observed between original soil $\mathrm{SC}$ and soils amended in the laboratory ( $\mathrm{SC}+\mathrm{A}$ and $\mathrm{SC}+\mathrm{CA}$ ), despite the increase in sorption. However, it should be noted that this increase in sorption upon amendment was much lower than that in sandy soil (Table 1). In the soil amended in the field (SC+FA), the diuron half-life was much lower than in the original soil SC, despite the similar sorption behavior

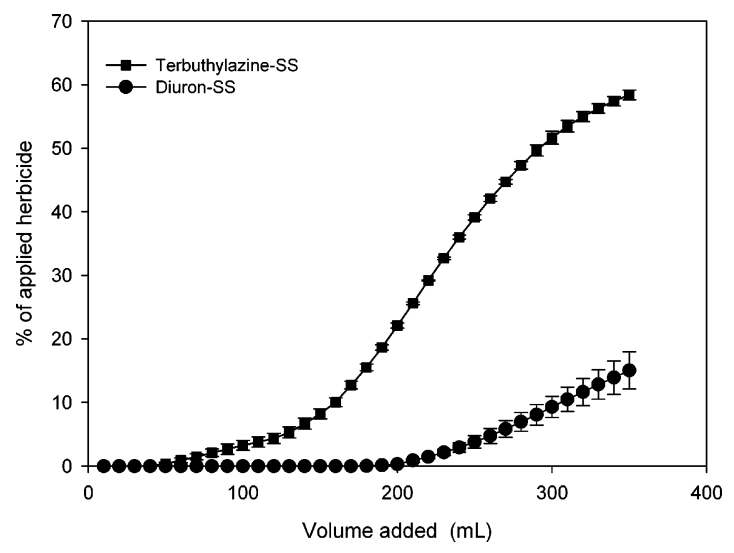

Figure 3. Cumulative leaching of diuron and terbuthylazine in SS soil.

observed, indicating that sorption was not the only process affecting degradation. Previous cropping history seems to be playing an important role in the rapid dissipation of diuron in SC+FA soil, because this soil had been treated in the field with diuron in the past 5 years, whereas soils amended in the laboratory $(\mathrm{SC}+\mathrm{A}$ and $\mathrm{SC}+\mathrm{CA}$ ) were not treated with diuron during this period. This agrees with data reported by Piutti et al. (36), who found that degradation rates of diuron, isoproturon, and pendimethalin were not affected after the first cropping cycle, but were significantly increased in planted soils after five cropping cycles.

A completely different behavior was observed with terbuthylazine (Figure 1; Table 1). Dissipation was very slow in the sandy soil, with a much longer half-life than that observed for diuron, despite the lower persistence reported for terbuthylazine than for diuron $(22,37)$. Small but significant differences were observed between SS and SS+A, despite the great increase in 
Table 2. Percentage of Diuron and Terbuthylazine Leached and Extracted from the Soil Columns after the Leaching Study

\begin{tabular}{|c|c|c|c|c|c|c|c|}
\hline \multicolumn{2}{|c|}{ soil } & SS & SS+A & SC & $\mathrm{SC}+\mathrm{A}$ & $\mathrm{SC}+\mathrm{CA}$ & $\mathrm{SC}+\mathrm{FA}$ \\
\hline diuron & $\begin{array}{l}\text { leached } \\
\text { extracted } 0-5 \mathrm{~cm} \\
\text { extracted } 5-10 \mathrm{~cm} \\
\text { extracted } 10-15 \mathrm{~cm} \\
\text { extracted } 15-20 \mathrm{~cm} \\
\text { total recovery }\end{array}$ & $\begin{array}{r}13.92 \pm 2.93^{a} \\
20.05 \pm 1.33 \\
15.17 \pm 2.01 \\
9.95 \pm 1.32 \\
4.30 \pm 0.10 \\
63.39 \pm 4.85\end{array}$ & \begin{tabular}{r}
\multicolumn{1}{c}{0} \\
$0.59 \pm 0.14$ \\
$10.47 \pm 1.63$ \\
$42.41 \pm 9.15$ \\
$32.21 \pm 10.2$ \\
$85.68 \pm 21.1$
\end{tabular} & 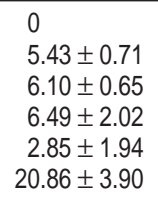 & \begin{tabular}{r}
\multicolumn{1}{c}{0} \\
$38.11 \pm 0.09$ \\
$10.21 \pm 4.98$ \\
$0.85 \pm 0.44$ \\
$0.81 \pm 0.38$ \\
$49.98 \pm 4.95$
\end{tabular} & \begin{tabular}{r}
\multicolumn{1}{c}{0} \\
$19.35 \pm 2.99$ \\
$17.64 \pm 0.81$ \\
$1.95 \pm 0.29$ \\
$0.46 \pm 0.07$ \\
$39.39 \pm 4.16$
\end{tabular} & \begin{tabular}{r}
\multicolumn{1}{c}{0} \\
$19.07 \pm 1.25$ \\
$39.78 \pm 2.47$ \\
$15.93 \pm 0.60$ \\
$0.60 \pm 0.12$ \\
$75.38 \pm 4.20$
\end{tabular} \\
\hline terbuthylazine & $\begin{array}{l}\text { leached } \\
\text { extracted } 0-5 \mathrm{~cm} \\
\text { extracted } 5-10 \mathrm{~cm} \\
\text { extracted } 10-15 \mathrm{~cm} \\
\text { extracted } 15-20 \mathrm{~cm} \\
\text { total recovery }\end{array}$ & $\begin{array}{r}58.38 \pm 0.76 \\
2.13 \pm 0.27 \\
3.01 \pm 0.27 \\
3.97 \pm 0.02 \\
6.70 \pm 0.18 \\
74.19 \pm 1.5\end{array}$ & 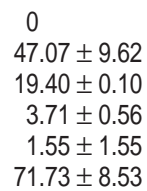 & $\begin{array}{r}1.68 \pm 0.45 \\
5.62 \pm 0.77 \\
18.18 \pm 2.47 \\
21.39 \pm 2.47 \\
8.72 \pm 0.16 \\
55.60 \pm 6.33\end{array}$ & $\begin{array}{r}2.43 \pm 0.65 \\
75.66 \pm 1.19 \\
9.70 \pm 1.57 \\
5.21 \pm 1.56 \\
5.26 \pm 0.39 \\
98.27 \pm 5.36\end{array}$ & $\begin{array}{r}1.50 \pm 0.53 \\
46.44 \pm 0.01 \\
36.20 \pm 3.01 \\
5.49 \pm 0.07 \\
3.59 \pm 0.37 \\
93.21 \pm 3.99\end{array}$ & $\begin{array}{r}3.59 \pm 0.27 \\
9.65 \pm 3.81 \\
19.29 \pm 1.68 \\
22.23 \pm 1.99 \\
6.26 \pm 2.70 \\
61.02 \pm 2.84\end{array}$ \\
\hline
\end{tabular}

${ }^{a}$ Numbers are mean value \pm standard deviation $(n=2) .{ }^{b}$ Total recovery $=$ leached + extracted.

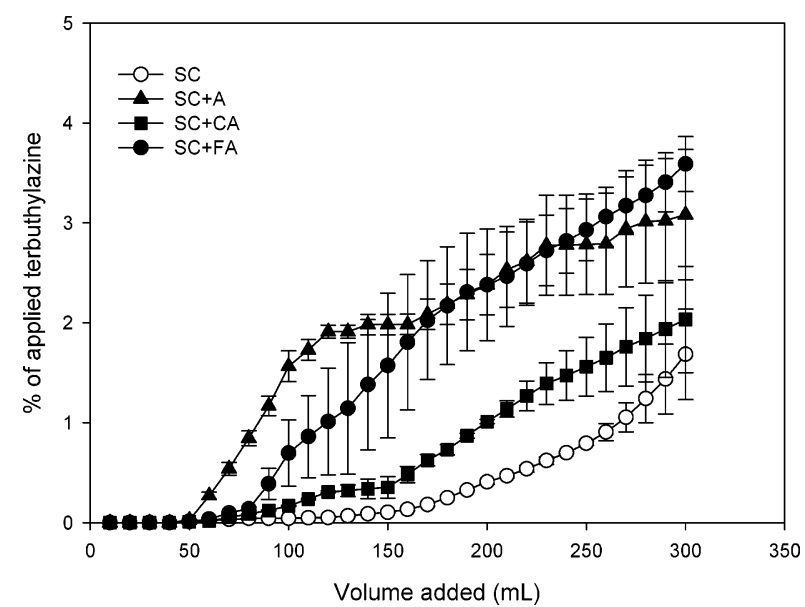

Figure 4. Cumulative leaching of terbuthylazine in unamended and amended SC soils.

terbuthylazine sorption in sandy soil upon amendment with alperujo (Table 1). In the case of the silty clay soil SC, the total amount of terbuthylazine dissipated was in every case lower in amended soils than in the original ones (Figure 1), especially in the case of soils amended in the laboratory, $\mathrm{SC}+\mathrm{A}$ and $\mathrm{SC}+\mathrm{CA}$, of higher organic matter content and sorption coefficients (Table 1). We did not find the rapid dissipation in the soil amended in the field ( $\mathrm{SC}+\mathrm{FA}$ ) as was observed in the case of diuron, which can be attributed again to the cropping history of the soil, because terbuthylazine was not applied in the past 5 years.

Diuron mineralization in SC soil after 6 weeks of incubation was low $(0.54 \pm 0.04 \%$ of applied $)$ and slightly lower in SC+A $(0.43 \pm 0.03 \%$ of applied). The effect of alperujo in terbuthylazine mineralization was greater than that in diuron. Terbuthylazine mineralization in unamended SC soil was $0.9 \pm 0.16 \%$ of applied, and when soil was amended with alperujo, the amount of terbuthylazine mineralized decreased to $0.27 \pm 0.2 \%$ of applied. These results do not agree with those reported by Gan et al. (32) and Wanner (38), who found increases in pesticide mineralization in amended soils due to an increase in soil microbial activity. However, similar results were obtained in ref 5 with terbuthylazine in a soil amended with urban sewage sludge and in ref 7 with simazine and a soil amended with alperujo. The latter attributed this lower mineralization in amended soils to a possible toxic effect of alperujo on soil microbial population. Alternatively, soil microorganisms in soils amended with alperujo may have preferentially used the organic matter of alperujo as a carbon and energy source instead of diuron or terbuthylazine and at the same time degraded the herbicides through co-metabolic reactions that do not cause $\mathrm{CO}_{2}$ release (7).

Photolysis Studies. Photolysis can be a significant abiotic degradation process affecting pesticides and other organic contaminants in water, soils, and plants. No changes in terbuthylazine solution concentration $(20 \mu \mathrm{M})$ were observed after $48 \mathrm{~h}$ of irradiation. Diuron photodegradation in aqueous solution $(20 \mu \mathrm{m})$ and photodegradation of diuron in SS and $\mathrm{SS}+\mathrm{A}$ soils are shown in Figure 2. Diuron concentration in the dark control (under the same conditions except for the light) did not significantly decrease (data not shown). Under the conditions studied, diuron half-life in aqueous solution was 18.8 $\mathrm{h}$. The half-life increased to $33.1 \mathrm{~h}$ in the sandy soil SS, and the increase is attributed to absorption of light by soil components and screening or light attenuation effect of the soil particles (39). When the soil was amended with alperujo, there was no photolysis. We did not observe a photosensitizing effect of the increase in organic matter, as reported for other pesticides in the presence of organic matter $(26,40)$. This can be attributed not only to the higher adsorption of diuron in SS+A soil when compared with that in unamended SC (Table 1) but also to the dark color of SS+A, which would have a light-filtering effect, protecting diuron molecules from photodegradation.

Leaching Studies. Diuron was detected in leachates from SS soil (Figure 3) and was not detected in leachates from $\mathrm{SS}+\mathrm{A}$ or any of the leachates of unamended or amended SC soil during the 30 day study, which can be attributed to the higher sorption in these soils (Table 1). The amounts of diuron extracted and leached from the soil columns are given in Table 2 . The total amount recovered in SS soil columns (leached + extracted) is much lower than that recovered in soil extraction of the SS+A column, which can be attributed to the higher persistence and higher sorption of diuron in SS+A than in SS (Table 1). In the case of SC soils, the higher recoveries correspond to $\mathrm{SC}+\mathrm{A}$ and $\mathrm{SC}+\mathrm{CA}$ soil columns, also of higher persistence and higher sorption but lower reversibility than unamended SC soil, especially in the case of SC+CA (Table 1). In the case of $\mathrm{SC}+\mathrm{FA}$, the amounts recovered are similar to that recovered from unamended soil $\mathrm{SC}$, which do not agree with the lower $t_{1 / 2}$ observed in dissipation studies (Table 1), suggesting that sorption prevails over dissipation, because both soils (SC and SC+FA) have similar sorption-desorption behaviors.

High amounts of terbuthylazine (nearly $60 \%$ of the applied herbicide) were recovered in leachates from SS soil (Figure 3), of very low sorption capacity, whereas no terbuthylazine 
was detected in leachates from SS+A. In the latter, very high recoveries were obtained after soil column extraction (Table 2), which can be attributed to the great increase in terbuthylazine sorption in SS upon amendment (Table 1). In the case of SC soil, low amounts of terbuthylazine were found in the leachates from soil columns (Figure 4), and the total amounts recovered from soil column extraction (Table 2) are very high in the more sorptive soils $\mathrm{SC}+\mathrm{A}$ and $\mathrm{SC}+\mathrm{CA}$ and similar for unamended SC and SC+FA soils, of similar sorption capacity (Table 1). Surprisingly, greater amounts were found in leachates from amended soils as compared to unamended soil, especially in the case of $\mathrm{SC}+\mathrm{A}$ and $\mathrm{SC}+\mathrm{FA}$, despite the increase in sorption upon amendment in $\mathrm{SC}+\mathrm{A}$ soil and the similar sorptiondesorption behaviors of SC and SC+FA. These results do not agree with those reported in ref 4; these authors found a decrease of simazine leaching in soils amended with solid olive mill waste, which could be due to specific interactions between terbuthylazine and soluble organic carbon (DOC) favoring movement through the soil columns. The higher DOC content of fresh alperujo $\left(25 \mathrm{~g} \mathrm{~kg}^{-1}\right)$ when compared to composted alperujo $\left(3 \mathrm{~g} \mathrm{~kg}^{-1}\right)$ and the lower HIX of the fresh alperujo (3 vs 13) can explain the higher amounts leached in $\mathrm{SC}+\mathrm{A}$ and $\mathrm{SC}+\mathrm{FA}$ when compared to $\mathrm{SC}+\mathrm{CA}$. These results would agree with those found in ref 41 , where a decrease in terbuthylazine recovery from DOC solutions was reported, suggesting DOC-terbuthylazine interactions, which again reveals the complexity and specificity of the processes involved in pesticide-soil-solution interactions in organically amended soils.

Conclusions. The addition of olive oil mill wastes, alperujo, from two-phase decanter centrifuges, either composted or untreated, can modify the sorption capacity of soil for diuron and terbuthylazine and subsequently their dissipation and leaching. With regard to the influence of amendments on sorption, our results show that the source and amount of OM can affect sorption and that these effects can be different for different classes of herbicides. We can also conclude that the addition of these organic amendments to soil does not always ensure slower dissipation or decreased leaching of the herbicides. Implications concerning specific interactions between the dissolved organic chemicals (DOC) of these amendments and the herbicides should be taken into account because, despite the increase in soil retention upon amendment with alperujo, leaching can be favored in the case of terbuthylazine. The possible slight increased leaching of terbuthylazine-DOC complexes would be counterbalanced by the fact that the application of fresh or composted alperujo to the land would appear to be an extremely effective contribution to increasing crop yields (9) and to maintaining or improving soil fertility if properly mixed and incorporated at acceptable loading rates. At the same time, this practice could mitigate a large potential environmental problem associated with olive oil production wastes.

\section{LITERATURE CITED}

(1) Borja, R.; Rincón, B.; Raposo, F. Review anaerobic biodegradation of two-phase olive mill solid wastes and liquid effluents: kinetic studies and process performance. J. Chem. Technol. Biotechnol. 2006, 81, 1450-1462.

(2) Martín, J.; Sampedro, I.; García-Romera, I.; García-Garrido, J. M.; Ocampo, J. A. Arbuscular mycorrhizial colonization and growth of soybean (Glycine max) and lettuce (Lactuca sativa) and phytotoxic effects of olive mill residues. Soil Biol. Biochem. 2002, 34, 1769-1775.
(3) Alburquerque, J. A.; Gonzálvez, J.; García, D.; Cegarra, J. Composting of a solid olive-mill by-product ("alperujo") and the potential of the resulting compost for cultivating pepper under commercial conditions. Waste Manage. 2006, 26, 620-626.

(4) Albarrán, A.; Celis, R.; Hermosín, M. C.; López-Piñeiro, A.; Cornejo, J. Behaviour of simazine in soil amended with the final residue of the olive-oil extraction proces. Chemosphere 2004, 54, 717-724.

(5) Navarro, S.; Vela, N.; García, C.; Navarro, G. Persistence of simazine and terbuthylazine in a semiarid soil after organic amendment with urban sewage sludge. J. Agric. Food Chem. 2003, 51, 7359-7365.

(6) Abu-Zreig, M.; Al-Widyan, M. Influence of olive mills solid waste on soil hydraulic properties. Commun. Soil Sci. Plant Anal. 2002, 33, 505-517.

(7) Albarrán, A.; Celis, R.; Hermosín, M. C.; López-Piñeiro, A.; Ortega-Calvo, J. J.; Cornejo, J. Effects of solid olive-mill waste addition to soil on sorption, degradation and leaching of the herbicide simazine. Soil Use Manage. 2003, 19, 150-156.

(8) Brunetti, G.; Plaza, C.; Senesi, N. Olive pomace amendment in Mediterranean conditions: effect on soil and humic acid properties and wheat (Triticum turgidum L.) yield. J. Agric. Food Chem. 2005, 53, 6730-6736.

(9) López-Piñeiro, A.; Fernandez, J.; Nunes, J. M. R.; GarciaNavarro, A. Response of soil and wheat crop to the application of two-phase olive-mill waste to Mediterranean agricultural soils. Soil Sci. 2006, 171, 728-736.

(10) The Pesticide Manual, 9th ed.; Worthing, C. R., Hance, R. J., Eds.; The British Crop Protection Council: Farnham, U.K., 1991.

(11) Field, J. A.; Reed, R. L.; Sawyer, T. E.; Griffith, S. M.; Wigington, P. J., Jr. Diuron occurrence and distribution in soil and surface and ground water associated with grass seed production. J. Environ. Qual. 2003, 32, 171-179.

(12) Tixier, C.; Sancelme, M.; Bonnemoy, F.; Veschambre, H. Fungal biodegradation of a phenylurea herbicide, diuron: structure and toxicity of metabolites. Pest Manage. Sci. 2000, 56, 455-462.

(13) Giacomazzi, S.; Cochet, N. Review. Environmental impact of diuron transformation: a review. Chemosphere 2004, 56, 10211032.

(14) Beernaerts, S.; Gerard, M.; Debongnie, P.; Barthelemy, J. P.; Pussemier, L.; Copin, A. Two years of pesticides monitoring in a Belgian watershed. Int. J. Environ. Anal. Chem. 2003, 83, 469480.

(15) Guzella, L.; Rullo, S.; Pozzoni, F.; Giuliano, G. Studies on mobility and degradation pathways of terbuthylazine using lysimeters on a field scale. J. Environ. Qual. 2003, 32, 10891098.

(16) Lányi, K.; Dinya, Z. Photodegradation study for assessing the environmental fate of some triazine-, urea- and thiolcarbamatetype herbicides. Microchem. J. 2005, 80, 79-87.

(17) Johannesen, H.; Aamand, J. Mineralization of aged atrazine, terbuthylazine, 2,4-D, and mecoprop in soil and aquifer sediment. Environ. Toxicol. Chem. 2003, 22, 722-729.

(18) Jacobsen, C. S.; Shapir, N.; Jensen, L. O.; Jensen, E. H.; Juhler, R. K.; Streibig, J. C.; Mandelbaum, R. T.; Helweg, A. Bioavailability of triazine herbicides in a sandy soil profile. Biol. Fertil. Soils 2001, 33, 501-506.

(19) Guzella, L.; Pozzoni, F.; Giuliano, G. Herbicide contamination of surficial groundwater in northern Italy. Environ. Pollut. 2006, 142, 344-353.

(20) Barriuso, E.; Calvet, R.; Houot, S. Field study of the effect of sewage sludge application on atrazine behaviour in soil. Int. J. Environ. Anal. Chem. 1995, 59, 107-121.

(21) Guo, L.; Bicki, T. J.; Hinesly, T. D.; Felsot, A. S. Effect of carbon-rich waste materials on movement and sorption of atrazine in a sandy, coarse-textured soil. Environ. Toxicol. Chem. 1991, 10, 1273-1282.

(22) The e-Pesticide Manual. A World Compendium, ver. 4.0, 14th ed.; Tomlin, C. D. S., Ed.; BCPC: Farnham, U.K., 20062007. 
(23) Nelson, D. W.; Sommers, L. E. Total carbon, organic carbon, and organic amendment. In Methods of Soil Analysis, part 2, 2nd ed.; Page, A. L., Miller, R. H., Keeney, D. R., Eds.; ASA and SSSA: Madison, WI, 1982; pp 539-579.

(24) Zolsnay, A. Dissolved humus in soil waters. In Humic Substances in Terrestrial Ecosystems; Piccolo, A., Ed.; Elsevier: Amsterdam, The Netherlands, 1996; pp 171-223.

(25) Zsolnay, A.; Baigar, E.; Jimenez, M.; Steinweg, B.; Saccomandi, F. Differentiating with fluorescence spectroscopy the sources of dissolved organic matter in soils subjected to drying. Chemosphere 1999, 38, 45-50.

(26) Cox, L.; Hermosin, M. C.; Cornejo, J.; Mansour, M. Photolysis of metamitron in water in the presence of soils and soil components. Chemosphere 1996, 33, 2057-2064.

(27) Gonzalez-Pradas, E.; Villafranca-Sanchez, M.; Fernandez-Perez, M.; Socias-Viciana, M.; Ureña-Amate, M. D. Sorption and leaching of diuron on natural and peat-amended calcareous soil from Spain. Water Res. 1998, 32, 2814-2820.

(28) Cox, L.; Velarde, P.; Cabrera, A.; Hermosín, M. C.; Cornejo, J. Dissolved organic carbon interaction with sorption and leaching of diuron in organic-amended soils. Eur. J. Soil Sci. 2006, in press.

(29) Felsot, A. S.; Shelton, D. R. Enhanced biodegradation of soil pesticides: Interactions between physicochemical processes and microbial ecology. In Sorption and Degradation of Pesticides and Organic Chemicals in Soil; Linn et al., Eds.; ASA and SSSA: Madison, WI, 1993; No. 32, pp 227-271.

(30) Topp, E.; Tessier, L.; Gregorich, E. G. Dairy manure incorporation stimulates rapid atrazine mineralization in an agricultural soil. Can. J. Soil Sci. 1996, 76, 403-409.

(31) Cox, L.; Celis, R.; Hermosin, M. C.; Becker, A.; Cornejo, J. Porosity and herbicide leaching in soils amended with olivemill wastewater. Agric. Ecosyst. Environ. 1997, 65, 151161.

(32) Gan, J.; Yates, S. R.; Papiernik, S.; Crowley, D. Application of organic amendments to reduce volatile pesticide emissions from soil. Environ. Sci. Technol. 1998, 32, 3094-3098.
(33) Scow, K. M.; Hutson, J. Effect of diffusion and sorption on the kinetics of biodegradation: theoretical considerations. Soil Sci. Soc. Am. J. 1992, 56, 119-127.

(34) Johnson, W. G.; Lavy, T. L.; Gbur, E. E. Persistence of triclopyr and 2,4-D in flooded and nonflooded soils. J. Environ. Qual. 1995, 24, 493-497.

(35) Fernandes, M. C.; Cox, L.; Hermosín, M. C.; Cornejo, J. Organic amendments affecting sorption, leaching and dissipation of fungicides in soil. Pest Manage. Sci. 2006, 62, 1207-1215.

(36) Piutti, S.; Marchand, A. L.; Lagacherie, B.; Martin-Laurent, F.; Soulas, G. Effect of croping cycles and repeated herbicide applications on the degradation of diclofop-methyl, bentazone, diuron, isoproturon, and pendimethalin in soil. Pest Manage. Sci. 2002, 58, 303-312.

(37) Spliid, N. H.; Helweg, A.; Heinrichson, K. Leaching and degradation of 21 pesticides in a full-scale model biobed. Chemosphere 2006, 65, 2223-2232.

(38) Wanner, U.; Fuhr, F.; Burauel, P. Influence of the amendment of corn straw on the degradation behaviour of the fungicide dithianon in soil. Environ. Pollut. 2005, 133, 63-70.

(39) Miller, G. C.; Zepp, R. G. Effects of suspended sediments on photolysis rates of dissolved pollutants. Water Res. 1979, 13, 453-459.

(40) Zamy, C.; Mazellier, P.; Legube, B. Phototransformation of selected organophosphorus pesticides in dilute aqueous solutions. Water Res. 2004, 38, 2305-2314.

(41) Giessl, H. DOM-flocculation: a suitable approach for separating free and DOM-bound herbicides? Environ. Sci. Pollut. Res. Int. 1999, 6, 77-82.

Received for review February 22, 2007. Revised manuscript received April 13, 2007. Accepted April 13, 2007. This work has been partially financed by Project AGL 2004-05818-CO2-01 from the Spanish MEC and Research Group RNM 124 of Junta de Andalucía. A.C. thanks the MEC for her FPI fellowship.

JF070525B 